\title{
Feasibility Study of Smart Grid in Bangladesh
}

\author{
Faysal Nayan ${ }^{1}$, Md. Aminul Islam², Shifat Mahmud ${ }^{3}$ \\ ${ }^{1}$ Department of EEE, Ahsanullah University of Science and Technology, Dhaka, Bangladesh \\ ${ }^{2}$ Deoartment of EEE, Ahsanullah University of Science and Technology, Dhaka, Bangladesh \\ ${ }^{3}$ Darmstadt University of Applied Science, Germany \\ Email: nayan102aust@gmail.com,md.aminul.bappy@gmail.com, shifatmahmud2013@gmail.com
}

Received 2013

\begin{abstract}
The agenda of this paper is to discuss about the significance and a detailed feasibility study of practical implementation of Smart Grid in Bangladesh. Smart grid refers to an electric power system that enhances grid reliability and efficiency by automatically responding to system disturbances. Power crisis is a major problem for a developing country like Bangladesh. Efficient transmission and distribution of electricity with essential energy resources is a fundamental requirement to provide citizens and economies. The paper analyzes the characteristics of Smart Grid and a comparative analysis with conventional grid system. It also discusses about the efficient transmission and distribution process which will integrate power system with renewable energy and information system.
\end{abstract}

Keywords: Smart Grid; Integration of Information and Power System; Centralized \& Distributed Generation System; Transmission and Distribution System; Performance Indicator; Renewable Energy

\section{Introduction}

The definition of smart grid is not uniform. It depends on the focus of the development of Smart Grid system. The main feature of Smart Grid is efficient energy system with reliability, flexibility, centralized and distributed power generation with fully automated power network [1, 2]. In recent days, most of natural resources are running out of phase. So, an energy efficient system is a global need to increase the utilization of generated power. Smart Grid can ensure such an efficient system. European Regulator Group for Electricity \& Gas (ERGEG) defined Smart Grid as, an electricity network that cost efficiently can integrate the behavior and actions of all users connected to it - generators, consumers and those that do both - in order to ensure a sustainable power system with low losses and high levels of quality, security of supply and safety. Renewable energy is an added advantage of Smart Grid. It can minimize our dependency on natural fuel resources. Most of the developed and developing countries are advancing to replace their conventional grid system with Smart Grid. To overcome the future impact in power sector Bangladesh should switch to Smart Grid $[3,4]$.

\section{Prospect of Smart Grid in Bangladesh}

Energy shortage is a worldwide concern. Presently, more than 40 countries show power system instability and load-shedding due to electricity shortage. North Ameri- can and European companies are presently working on building 'smart electrical grid' technologies to optimize energy flow using digital radios for more efficient electrical grid control and energy conservation. The need to build Smart Grid technologies is rising worldwide and Bangladesh can become a pioneer in this area of technology development. Since energy demand is increasing every year in Bangladesh, it is not possible to build power stations rapidly. Smart Grid system can minimize this problem. In the event of load-shedding, caused by electrical energy shortage in the country, the Smart Grid can automatically recalculate and distribute electricity to all consumers fairly [2,5].

The basic needs to implement Smart Grid are digital radios, circuit breakers etc. Both digital radios and circuit breakers are required to upgrade the operation of nation's electrical grid, which can be designed and manufactured in Bangladesh in large scale. With the help of expatriate Bangladeshi engineers, Bangladesh can start designing and manufacturing the electrical parts required to upgrade the electricity grid in Bangladesh so that, Bangladesh can be an early developer and adopter of the Smart Grid technology[1, 2].

\section{Comparison between Conventional Grid and Smart Grid}

Obviously there is a far difference between the conventional grid and Smart Grid system. Smart Grid ensures an energy efficient system. In Bangladesh the electric power 
grid has the conventional technique of one way delivery. So there are deregulations in the system. But recently conventional grid has been modernized since last few years. SCADA system, microcontroller based relays, automated power plants etc. already have been implemented $[1,5]$. So the proposition of smart grid could be a probable solution to minimize power crisis problem. The major requirement of smart grid is an automated network using broadband connection. A comparison between the conventional grid and Smart Grid is given in table $\mathbf{1}$ based on the characteristics of the grid system.

Table 1. Comparison between conventional grid and smart grid [1,4]

\begin{tabular}{|c|c|}
\hline Characteristics & Conventional Grid \\
\hline Communication method & Unidirectional, Not Real-time \\
\hline Technological base & Analog/Electromechanical \\
\hline Power flow control & Limited \\
\hline Power supply method & Centralized power Generation \\
\hline Self-heals & Responds to prevent further damage. \\
\hline Operation and Management & Artificial device calibration \\
\hline System topology & Radial structure \\
\hline Control system & Regional \\
\hline $\begin{array}{l}\text { Motivates \& includes the } \\
\text { consumer }\end{array}$ & $\begin{array}{l}\text { Consumers are uninformed and no } \\
\text { participative with the power system }\end{array}$ \\
\hline $\begin{array}{l}\text { Provides power quality for } 21^{\text {st }} \\
\text { century needs }\end{array}$ & $\begin{array}{l}\text { Focused on outages rather than power } \\
\text { quality problems. }\end{array}$ \\
\hline $\begin{array}{l}\text { Accommodates all } \\
\text { generation }\end{array}$ & $\begin{array}{l}\text { Relatively small number of large generat- } \\
\text { ing plants. }\end{array}$ \\
\hline Enables markets & $\begin{array}{l}\text { Limited wholesale markets still working } \\
\text { to find the best operating models. }\end{array}$ \\
\hline $\begin{array}{l}\text { Optimizes assets and operates } \\
\text { efficiently }\end{array}$ & $\begin{array}{l}\text { Minimal integration of limited operational } \\
\text { data with Asset Management processes } \\
\text { and technologies. }\end{array}$ \\
\hline Emergency recovery & Manual recovery \\
\hline Price Information & Limited \\
\hline Customer choice & Limited choice of optional function \\
\hline
\end{tabular}

\section{Integration of Information System}

Smart grid will integrate all the components of power system with information system to enhance the performance of the grid. Much of the integration of components relates to communication systems, IT and business processes. Real-time information and power exchange between elements of the Smart Grid requires high-speed, fully integrated and two-way communication with third party entities. The smart grid is based on the usage of smart energy technologies, the application of power control by means of digital information systems (smart meters and smart appliances) that communicate through the advanced communication technology (i.e. internet) with the electricity utility to optimize electrical power system generation, distribution and end-use energy demands $[1,6]$.

The communication between smart grid components is important for real time operation. Smart grid communication system can be divided into 3 groups; generation resources group, network group and load group, so that all the components can co-operate to ensure an efficient operation of the system. The generation resources group includes all power plants, storage and distributed generation systems, the network group performs the real time communication between the generation and load demand due to operate the load management system. Figure 1 shows the basic proposed structure of smart grid communication system.

Electric utilities use a wide variety of telecommunications including [1]:

a) Wired and Wireless Telephone.

b) Voice and Data Dispatch Radio.

c) Fiber Optics.

d) Power Line Carrier.

e) Satellite.

f) The Internet 


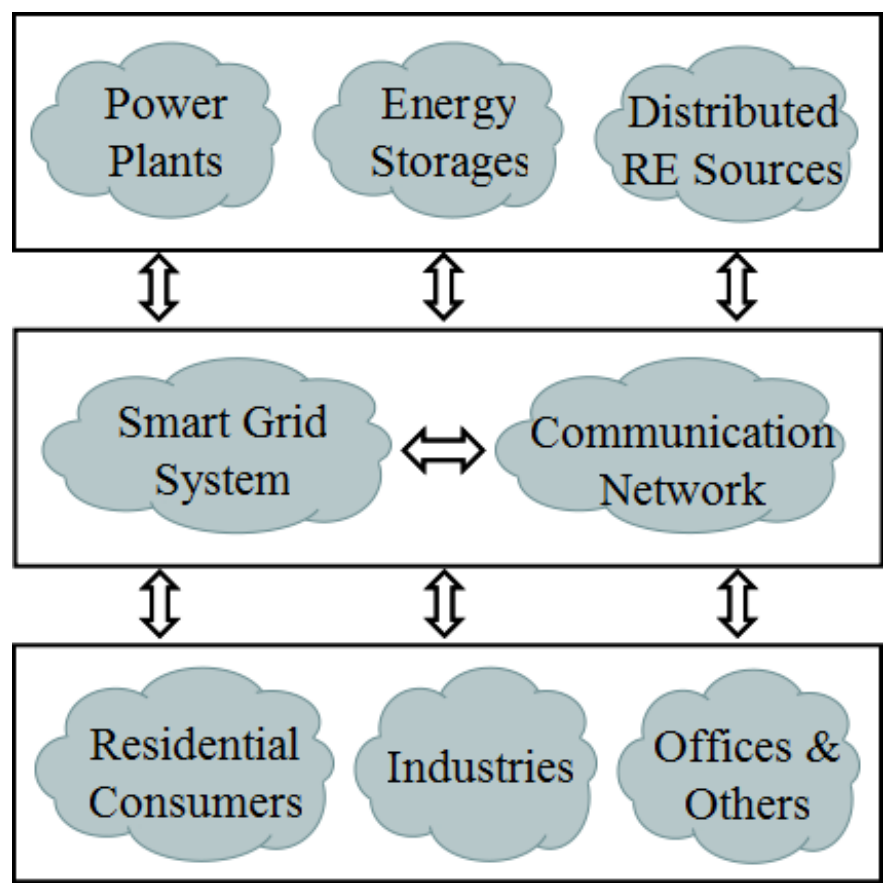

Figure 1. Simplified diagram of smart grid communication system

\section{Transmission Process of Smart Grid}

Electric power transmission system is used to transfer the electric energy from the generation unit through high voltage transmission lines which is distinct from the local wiring between high voltage substations and customers. Transmission systems already have some instrumentation that allows control centers to monitor power flows and operating circuit breakers at substations. Today, the transmission grid has a high-level of observation and some basic remote control. The basic transmission parameters - voltage, frequency and current - are well monitored and understood. However, there is much more that can be done[7,8].

\subsection{Measurement of Phase and Other Advanced Measurements}

In the smart grid transmission systems power flows measure automatically and provide report to control centers quickly. There is also providing some additional information that could be collected to improve dramatically the control and stability of high voltage grids. The voltage and current in the Bangladesh power system oscillates at a frequency of 50 cycles per second $(50 \mathrm{~Hz})$. In order to move power over a long line, there has to be a difference in phase between the two ends of the line, but if that difference becomes too great, the line will no longer transmit power. There are very few measurements of phase being made across today's transmission systems. With many more measurements at key locations, and with high-speed communication and advanced control systems to make use of the data, the efficiency and stability of power system operation could be improved substantially in the smart grid transmission system [8].

\subsection{FACTS and Other Advanced Control Device} Smart grid transmission system consists of a family of devices based on solid-state power electronics those can change the electrical properties of lines and make power flow where it is wanted. These Flexible AC Transmission System control devices are called FACTS devices. Now a day in smart grid system few utilities have started to use them when they are the most cost-effective way to solve a transmission problem. The control of FACTS requires advanced communication and system level control technology.

Many advanced technologies and strategies could be used to turn the high voltage transmission system into what some have termed a smart self-healing grid. A few important things could be done today. However, before the more advance ideas can be implemented, additional research and small-scale demonstration will be needed [8].

\section{Distribution System in Smart Grid}

Electric distribution system is a network which carries 
electricity from the transmission system and delivers it to end customers through the high voltage transmission system and then at lower voltage through the distribution system. When talk about Smart Grid which includes several things that can be done to improve the control and operation of distribution systems [8].

Distribution system of smart grid includes: Distribution

System Automation, Selective Load Control, Managing

Distributed Generation, smart meter.

\subsection{Distribution System Automation}

In smart grid distribution system all the power enters at one point and then flows out to the loads along the branches of the distribution feeder to the customers. Some utilities have added sensors and remote control switches that can isolate and cut off any problem. A number of power companies have already found it costeffective to install distribution system automation [8].

\subsection{Selective Load Control}

At present, if we want to isolate one portion of the system the only way to do this is by disconnecting entire distribution feeders. It would be far better to be able to control individual loads along a distribution feeder so that critical services such as police stations can remain connected, while loads that provide less critical services can be dropped. With a combination of smart meters and advanced distribution automation, this is possible in the smart grid system [8].

\subsection{Managing Distributed Generation}

In smart grid system use small distributed generators that both make electricity and produce usable heat energy. They make more efficient use of the energy of the fuel that is used; they can relieve stresses on transmission and distribution systems; and, they can increase the reliability of power supply to local customers. In an emergency, it would sometimes be desirable to be able to disconnect a distribution feeder from the main power system. However, with the right technology, control systems, and regulatory environment, there is no reason why we could not do this in a safe and efficient manner. Changes are needed to allow the development and wider use of distributed generation and small micro-grids $[6,8]$.

\subsection{Smart Meter}

The intelligent electronic device Smart meters serve as a sensor network to achieve information exchange between load-side and network. It is a computerized replacement of the electrical meter attached to the outer walls of many of our homes today. Each smart meter contains a processor, nonvolatile storage, and communication facilities. Its main functions are hourly pricing, power quality detection, remote switching function and pre-paid fees function. Smart meters can track usage as a function of time of day, disconnect a customer via software, or send out alarms in case of problems $[1,2,4]$.

\section{Integration of Renewable Energy}

Since penetration levels of renewable energy are likely to continue increasing a rethink of the existing energy balancing paradigm may be required. Fortunately, an operational smart grid has the potential to mitigate some of the difficulties that are posed by high levels of renewable energy generation. A smart grid takes advantage of potential improvements that can be made to conventional operation through the use of communications and information. Current power system is unable to predict and detect such variability and therefore cannot support or control this. Besides effects on the grid varies with different penetration levels of wind and solar energy. Thus reliability is a major concern now. So, a sensitive control system is required which will consist efficient transmission, demand response and intelligent energy storage in other words a smart grid can be adapted [5, 7].

An energy storage system is required to implement renewable energy sources. While renewable energy cannot necessarily be operated in a conventional manner, its behavior can be predicted and the forecast information is exactly the kind of information that a smart grid must use to improve system efficiency. So, simply we can see that renewable energy is an added advantage to Smart Grid [5].

\section{Performance Indicator for Future Smart Grid}

Smart Grid co-ordinate the needs and capabilities of all generators, grid operators, end-users and electricity market stakeholders. It operates all parts of the system as efficiently as possible, minimizing costs and environmental impacts while maximizing system reliability, resilience and stability. There is some indicator that measures that performance of smart grid [2, 3].

a) Quantified reduction of carbon emissions.

b) Environmental impact of electricity grid infrastructures.

c) Power system stability performance.

d) Percentage utilization of electricity grid elements.

e) Hosting capacity for distributed energy resources in distribution grids.

f) Ratio of reliably available generation capacity and peak demand.

g) Voltage quality performance of electricity grids.

h) Level of losses in transmission and in distribution networks. 


\section{Challenges to Implement Smart Grid}

Switching to smart grid from conventional grid is not an easy task. Though energy consumption growth is high, generation is failing to meet demand rate. A global statistics on energy consumption is given below:

Challenges required to meet the implementation of smart grid can be divided into two different types; security challenges and integration challenges [2-4].

We can forecast our global energy consumption growth from 2007 to 2050 by Figure 2 [9].

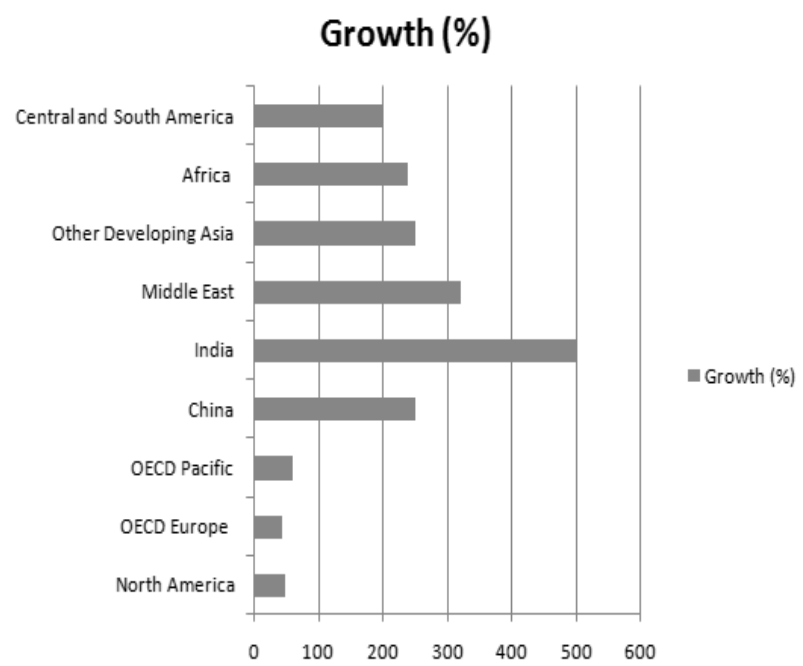

Figure 2. Forecasted global energy consumption growth (2007 to 2050)

\subsection{Security Challenges}

1. Network security of distributed systems across meters, substations and in-home devices including authentication, detection, and monitoring.

2. Identity \& access management for managing customer information.

3. Messaging and application security communications including data, network communications, and transactions.

4. Security policy management and implementing web services security standards.

\subsection{Integration Challenges}

1. Adoption of SOA architecture.

2. Web service enablement of legacy apps.

3. Format bridging, transformation and routing.

4. Handling wide variety of non-XML data formats.

5. Interfacing with partners and customers.

\section{Conclusion}

Energy shortage has become a global challenge. As the country economy is mostly dependent on electrical energy, each and every nation is trying to recover their energy crisis. A developing country like Bangladesh needs an efficient energy system to minimize the losses and proper utilization of generated power. Smart Grid system is the only one and proper solution. Bangladesh has better prospect to implement Smart Grid technology. It is possible to manufacture the equipments required to implement Smart Grid in Bangladesh. Only some alteration is needed to make it happen. At the same time some moderation in transmission and distribution system can be done. So Smart Grid can be a proper solution for Bangladesh to overcome the power crisis problem and to face the future impacts in power sector [1-4].

\section{REFERENCES}

[1] X. S. Zhou, L. Q. Cui and Y. J. Ma, "Research on Smart Grid Technology,” 2010 IEEE International Conference on Computer Application and System Modeling (ICCASM-2010), Vol. 3, 2010, pp. 599-603.

[2] C. W. Potter, A. Archambault and K. Westrick, "Building a Smarter Smart Grid through Better Renewable Energy Information," IEEE Power Systems Conference and Exposition, 2009 (PSCE '09), 2009, pp. 1-5.

[3] J. Stragier, L. Hauttekeete and L. De Marez, "Introducing Smart Grid in Residential Context's: Consumers' Perception of Smart Household Appliances,” 2010 IEEE Conference on Innovative Technologies for an Efficient and Reliable Electricity Supply (CITRES 2010), 2010, pp. 135-142.

[4] Position Paper on Smart Grids, “An ERGEG Conclusions Paper,” European Regulator Group for Electricity \& Gas (ERGEG), 10 June 2010

[5] Vision and Strategy for Europe's Electricity Networks of the Future, European Smart Grids Technology Platform, Directorate-General for Research Sustainable Energy Systems, EUR 22040.

[6] Technology Roadmap, Smart Grids, International Energy Agency (IEA).

[7] ROA Group Korea Consultants, Introduction to Smart Grid, Research on Asia (ROA) Group White Paper, July, 2009.

[8] Electric Power Transmission and Distribution [EPTD] Smart Grid Program.

[9] The Financial Express [http://www.thefinancialexpress-bd.com/] 